\section{Meeting calls for international trials database}

Information on all worldwide active and completed randomized controlled clinical trials should be made available through a central database to avoid unnecessary duplication of medical research, participants at an international meeting held in London on 4 October insisted.

Such a database would prevent unethical testing of patients, whose enrollment in trials might add little value to current knowledge; prevent wastage of public research funds; promote research cooperation; and flush into the open negative results that now escape publication.

The detrimental effect of publishing only positive medical information is widely acknowledged. In an example of biased under-reporting of negative data, lain Chalmers, director of the UK Cochrane Centre, Oxford, cited the case of the antiarrhythmic drug lorcainide. A 1980 study that revealed increased mortality of the drug went unpublished for 13 years because researchers thought that the increased death rate "was an effect of chance." This class of drug was used in the intervening period and has been associated with thousands of deaths.

The UK has 3,000 trials involving half a million people taking place at any one time. Databases are maintained by the Cochrane center, the Medical Research Council and the largest by the National Health Service. The UK's Chief Medical Officer, Liam Donaldson, voiced his support for a centralized database, but did not say who would fund or coordinate the effort.

Such a database would be incomplete without trial information from private companies, and so far only two pharmaceutical companies-Schering Plough and Glaxo Wellcome-have committed to making data on licensed products available. It is unclear whether other companies will volunteer similar information.

According to Alexa McCray from the US National Library of Medicine (NLM), the Food and Drug Administration Modernization Act of 1997 requires that a registry of trials for both private and federally funded work in the area of "serious and lifethreatening conditions" is created by the NLM. This database will be publicly accessible in January 2000, but will only contain information on active trials in which patients may wish to enroll. It will not contain results from completed trials.

KAREN BIRMINGHAM, LONDON

\title{
Complaint upheld against university ethics committee
}

A British university has been found guilty by an internal committee of failing to take adequate provisions to protect the interests of subjects involved in a study of individuals who assist AIDS patients to commit suicide.

The complaint against the University of Exeter was lodged by a postgraduate researcher, Canadian criminologist Russel Ogden, who abandoned the study because he felt that the university was not prepared to take sufficiently rigorous steps to protect the identities of those involved in his research.

In particular, Ogden wanted to ensure that he would not be required to provide the names of those contacted during his research to the police at a later date. His concern was based on earlier experience: when conducting research for a masters thesis at Simon Fraser University in Canada in he early 1990's, Ogden had to fight off demands from a coroner's court to reveal the identity of individuals who he had interviewed on a confidential basis.

A board of inquiry set up to investigate Ogden's complaints at Exeter, headed by a deputy vice-chancellor at the university, rejected a number of lesser charges that Ogden had levelled against the university. For example, these related to disputes with the sociology department over the writing up of this thesis, and over what he described as a "suffocating silence" surrounding the issues that he was raising. But on the main charge-that of failing to make adequate provisions to ensure that the identity of informants be protectedthe board of inquiry concluded that the ethical approval of Ogden's PhD research was "mishandled," and demonstrated "serious incompetence and subsequent misjudgement" by the department of sociology in which he was working.

The board also found that there was a "casual attitude" towards maintaining consistency in the actions of the department of its written records. And it described the university ethics committee of offering an "inert response" to a report by the sociology department on its ethical approval of Ogden's PhD thesis.

Ogden insists that the case has exposed major shortcomings in the approach of British universities to providing adequate protection for human subjects in potentially sensitive research. "In Britain...many researchers still seem to hold the view the their work is ethical by definition; there is this 'nanny mentality' that what we are doing is automatically good for the subject, so trust us."

A spokesman for the university says that a set of recommendations is being drawn in response to the criticisms made by the inquiry, and that these will be put to the University Senate shortly.

DAvid Dickson, LoNDON

\section{Drug company settles AIDS drug suit with US university}

The University of Minnesota in Minneapolis could receive up to $\$ 300$ million in royalty payments over the next decade from the sale of Glaxo Wellcome's (GW) new reverse transcriptase inhibitor drug, Ziagen, following an out-of-court settlement of a patent lawsuit with the pharmaceutical company last month.

Ziagen was developed from a class of carbocyclic nucleocide compounds discovered and patented in the late 1980s by university professor Robert Vince, and licensed to GW's pre-merger company, Burroughs Wellcome. The drug was approved by the Food and Drug Administration in December 1998. Despite earlier denials that it owed royalties on the AIDS drug to the university, GW agreed to hand over initial payments totaling $\$ 8.25$ million to the university by 23 October. The remaining royalty fees will be paid as an incremental percentage of drug sales.

Vince, and colleague Mei Hua, will receive one-third of the settlement, and under federal law the remainder will go to the university to be used for research and education. One-quarter of those funds will go back into Vince's department to support graduate fellowships and build a new drug design center.

Vince, who worked as a post-doc in the laboratory where the first antiviral drug, acyclovir, also manufactured by GW, was discovered, says that the lawsuit has been a "far bigger disruption to his work than he anticipated," but that he pursued the claim to gain scientific recognition for his work on the drug.

KAREN BIRMINGHAM, LONDON 